\title{
Liquid metals and liquid carbon: some similar properties at high temperatures
}

\author{
V.E. Fortov, V.N. Korobenko, and A.I. Savvatimskiy \\ 125412, Izhorskaya, 13, Bd2, Joint Institute for High Temperatures RAS, Moscow, Russia.
}

\begin{abstract}
.
Liquid carbon resistivity $\rho$ (just after the melting) diminishes with rising of input energy and pressure $\mathrm{P}$ (for $\mathrm{P}$ - lower than $50 \mathrm{kbar}$ ). Far above melting point, at high pressure (higher $\sim 50 \mathrm{kbar}$ ) liquid carbon resistivity rises sharply, up to $3000 \mu \Omega \cdot \mathrm{cm}$. It was shown that the liquid carbon (as some other metals, for example W, Li) has one and the same property: a denser phase (in liquid state) has higher resistivity.
\end{abstract}

\section{Introduction}

Planets of our solar system (Mercury, Venus, Earth and Mars) are made out of silicates on the base of Si. However, it has been proposed by the astronomers [1] in 2005, that planets made mostly out of carbon could exist. Carbon planets are believed to be frequent near the center of the galaxy, since the concentration of carbon is higher than near the Solar system. The main content of carbon planet should be a carbon in different phase states. An experimental confirmation was appeared in 2010 [2]: an analysis of multi-wavelength photometry in the atmosphere of exoplanet WASP-12b shows a high content of $\mathrm{C}$ in its atmosphere. That is why to know the carbon properties at high $\mathrm{P}$ and $\mathrm{T}-$ is the main task of the high pressure physics.

\section{Experimental setup}

The experimental method used for metals and carbon investigation was fast heating by unitary pulse of electrical current, using a $20 \mathrm{~kJ}$ storage capacitor bank of low inductance facilities. The pulse heating of the graphite specimens placed into the sapphire thickwalled capillary tubes was accomplished by discharging a $72-\mu \mathrm{F}$ capacitor bank at a charging voltage of $20 \mathrm{kV}$. It is not necessary to take into account the heat losses and chemical reactions for the short duration of the experiment $(1-5 \mu \mathrm{s})$. The average pressure in a carbon specimen equals to $4.5 \mathrm{kbar}$ due to the pinch-effect only for the $70 \mathrm{kA}$ current. Diagnostic equipment included a digital 4-channel oscilloscope Tektronix TDS-754C for recording signals from voltage and current transducers.

\section{Data on the liquid carbon properties}

Melting point of the carbon was discussed in [3]. Our results on carbon expansion obtained in sapphire capillary tubes (and between sapphire plates) at the melting line are shown in the Table $1[3,4]$. Togaya [5] obtained linear dependence between rising pressure $\mathrm{P}$ and diminishing of the imparted energy $E_{M}$ at the finish of melting. $\mathrm{E}_{\mathrm{M}}=20.8 ; 18.3 \mathrm{~kJ} / \mathrm{g}$ correspond to pressure $\mathrm{P}=25 ; 40$ kbar accordingly (shown with bold in Table1 [5]). We did not recording pressure. It was roughly estimated by comparison with the $\mathrm{E}_{\mathrm{M}}$ and resistivity data [5] (steady state measuring pressure under pulse heating: relative resistivity diminishes with rising pressure up to $50 \mathrm{kbar})$. All the data in Table1 are for dense graphite $\left(2.2 \mathrm{~g} / \mathrm{cm}^{3}\right)$.
Table 1. Resistivity $\rho$ and pressure $P$ for liquid carbon at the melting line under $\mathrm{E}_{\mathrm{M}}\left(V_{0}-\right.$ initial volume).

\begin{tabular}{|l|l|l|l|l|l|}
\hline $\begin{array}{l}\mathrm{E}_{\mathrm{M}} \\
\mathrm{kJ} / \mathrm{g}\end{array}$ & $\begin{array}{l}\mathrm{P} \\
\mathrm{kbar}\end{array}$ & $\begin{array}{l}\rho^{0} \\
\mu \Omega \cdot \mathrm{cm}\end{array}$ & $\begin{array}{l}\rho^{0}\left(V / V_{0}\right) \\
\rho^{0} \\
\mu \Omega \cdot \mathrm{cm}\end{array}$ & $\begin{array}{l}\gamma \\
\mathrm{g} / \mathrm{cm}^{3}\end{array}$ & $\begin{array}{l}V / V_{0} \\
\text { Relative } \\
\text { expansion }\end{array}$ \\
\hline 21 & 23.5 & 590 & 730 & - & $\begin{array}{l}\text { Between } \\
\text { sapphire plates }\end{array}$ \\
\hline $\mathbf{2 0 . 8}$ & $\mathbf{2 5}$ & $\mathbf{5 7 2}$ & - & - & - \\
\hline 19 & 36 & 552 & 690 & 1.76 & 1.25 \\
\hline 18.7 & 38 & 547 & 640 & 1.88 & 1.17 \\
\hline $\mathbf{1 8 . 3}$ & $\mathbf{4 0}$ & $\mathbf{4 8 3}$ & - & - & - \\
\hline
\end{tabular}

It was shown in Table 1(for high initial density 2.2 $\mathrm{g} / \mathrm{cm}^{3}$ ) that the liquid carbon resistivity $\rho$ diminishes from 590 to $483 \mu \Omega \cdot \mathrm{cm}$ (referred to initial volume) at the melting line with the simultaneously rising of the pressure $\mathrm{P}$ (from 23.5 to $40 \mathrm{kbar}$ ).

The results of microsecond heating [6] for the graphite of low initial density $\gamma_{0} \sim 1.83 \mathrm{~g} / \mathrm{cm}^{3}$ at low pressure (4 kbar of gas pressure) give approximately constant liquid carbon resistivity $\sim 1000 \mu \Omega \cdot \mathrm{cm}, \quad$ up to the temperature $6000 \mathrm{~K}$.

The results of liquid carbon specific electrical resistivity for three graphite specimens heated in sapphire capillary tubes are shown in Fig.2. The curves are shown from the start of isochoric heating begins with the finish of melting (arrows). As it was stated earlier carbon expansion has attained nearly twice volume up to the finish of melting. All the curves related to the isochoric heating in Fig. 3 express the constant density $\gamma$ $\left(\gamma=1.1 \mathrm{~g} / \mathrm{cm}^{3}\right.$ for the curve $1 ; \gamma=1.76 \mathrm{~g} / \mathrm{cm}^{3}$ for the curve $2 ; \gamma=1.88 \mathrm{~g} / \mathrm{cm}^{3}$ for the curve 3 ).

One can see that the end of melting begins at a higher input energy for lower density (lower pulse pressure) curve 1 . The melting has been completed at a lower input energy with higher pressure for other curves. We can underline 3 main peculiarities of the liquid carbon resistivity behavior (Fig.2), as it follows. The first: Liquid carbon resistivity at the melting point decreases with increasing of density as it can be seen in figure 2 (arrows show 790, 690, and $640 \mu \Omega \cdot \mathrm{cm}$ for curves 1, 2, and 3 , accordingly). One may consider $\mathrm{d} \rho / \mathrm{dP}<0$ for liquid carbon just at the melting point, which coincides with the data published in [5] for pressure $\mathrm{P}<50 \mathrm{kbar}$ also at the melting point.

This is an Open Access article distributed under the terms of the Creative Commons Attribution-Noncommercial License 3.0, Dwhich permits unrestricted use, distribution, and reproduction in any noncommercial medium, provided the original work is properly cited. 


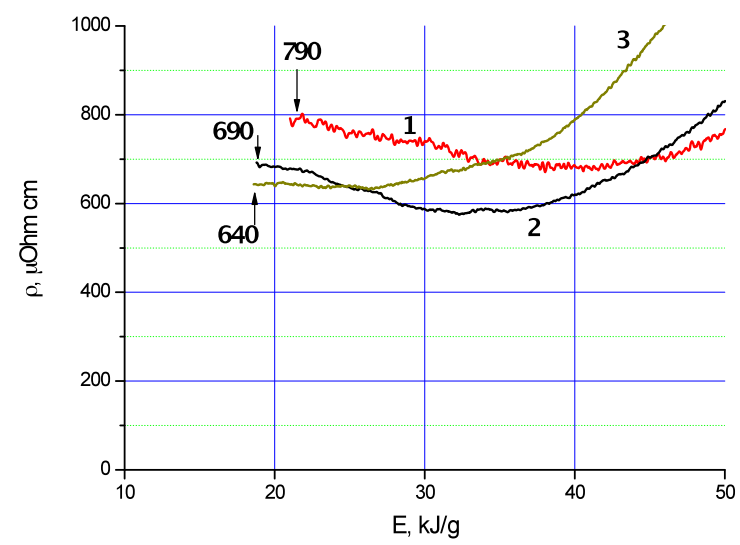

Fig.2. Specific resistivity $\rho$ (with the expansion included) of the carbon versus input energy E. Thermal expansion (up to the inner sapphire volume) included starting with the finish of melting (arrows). Beginning with the marked arrows isochoric heating is established. Curve $1-\mathrm{V} / \mathrm{V}_{0}=2.0$; density $\gamma=1.1$ $\mathrm{g} / \mathrm{cm}^{3}$. Curve $2-\mathrm{V} / \mathrm{V}_{0}=1.25$; density $\gamma=1.76 \mathrm{~g} / \mathrm{cm}^{3}$. Curve 3 $-\mathrm{V} / \mathrm{V}_{0}=1.17$; density $\gamma=1.88 \mathrm{~g} / \mathrm{cm}^{3}$.

The second: for the lower density $\left(1.1\right.$ and $\left.1.76 \mathrm{~g} / \mathrm{cm}^{3}\right)$ resistivity falls down just after melting. It looks like nonmetallic behavior.

The third: the decrease of resistivity $\rho$ with the increase of energy input $\mathrm{E}$ just near the melting point transforms to the increase of resistivity at high energy input $(\mathrm{d} \rho / \mathrm{dE}$ $>0)$. For example, at $\mathrm{E}=45 \mathrm{~kJ} / \mathrm{g}$ for the curve $1(\gamma=$ $\left.1.1 \mathrm{~g} / \mathrm{cm}^{3}\right)$, the resistivity $\rho$ is the lowest and for curve 3 $\left(\gamma=1.88 \mathrm{~g} / \mathrm{cm}^{3}\right)$, the resistivity has the highest value. The last is clearly seen also in the figure 3 for higher input energy level (up to $75 \mathrm{~kJ} / \mathrm{g}$ ) for the same specimens.

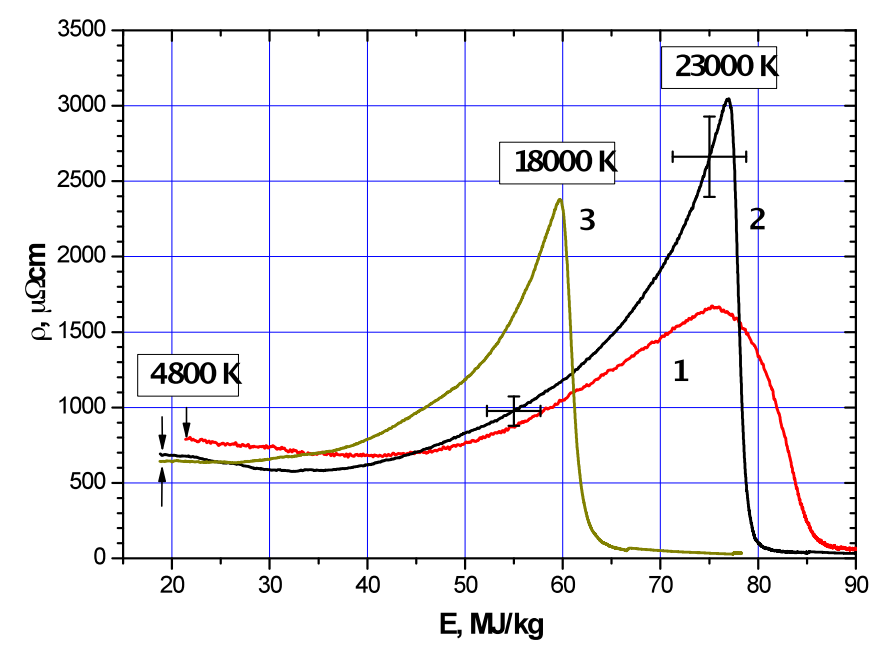

Fig.3. Specific resistivity of the liquid carbon under isochoric heating in sapphire thick-walled capillary tubes.

In the present experiments with the graphite specimens pulse installation gives electrical current of $\sim 70 \mathrm{kA}$ for heating of graphite specimen with the diameter $0.7 \mathrm{~mm}$ (length $10-15 \mathrm{~mm}$ ). The duration of heating is nearly 3 4 microseconds. The main part of this report is referring to fast heating of anisotropic graphite of high initial density $\left(2.25 \mathrm{~g} / \mathrm{cm}^{3}\right)$. This grade of graphite has low initial resistivity $(\sim 200 \mu \Omega \cdot \mathrm{cm})$. The experiments were fulfilled in the sapphire capillary tubes. The input energy reaches meltin

$\mathrm{g}$ region (from $\sim 10.5 \mathrm{MJ} / \mathrm{kg}$ up to $\sim 20.5 \mathrm{MJ} / \mathrm{kg}$ ), and then the electrical resistivity of liquid carbon diminishes under further isochoric heating. It looks like a non metal behavior for liquid carbon. As we supposed this diminishing lasts up to the rising pressure near to $\sim 50$ kbar (according to M.Togaya data [5]). A high pulse pressure has appeared in a restricted volume of the tube begin with the finish of melting. Liquid carbon resistivity begins rising at high input energy (35-45 $\mathrm{MJ} / \mathrm{kg})$ and reached high value $(\sim 3000 \mu \Omega \cdot \mathrm{cm})$ at the highest input energy of $75 \mathrm{MJ} / \mathrm{kg}$ (figure 3 ). Uncertainties in measuring input energy and resistivity are shown for curve 2 at 55 and $75 \mathrm{MJ} / \mathrm{kg}$.

Pulse heating from $\mathrm{E}=0$ to the melting region is excluded. Isochoric heating started from the end of melting (arrows at $4800 \mathrm{~K}$ ). The peaks of all the curves show the start of the tube destruction. 1 - Density in liquid state $\gamma=1.1 \mathrm{~g} / \mathrm{cm}^{3} ; 2$ - Density in liquid state $\gamma=$ $1.76 \mathrm{~g} / \mathrm{cm}^{3} ; 3$ - Density in liquid state $\gamma=1.88 \mathrm{~g} / \mathrm{cm}^{3}$.

Isotropic graphite MF-307 (Nippon-Carbon Ltd. production) was heated also in the sapphire capillary tubes. It has initial density $2.0 \mathrm{~g} / \mathrm{cm}^{3}$ and high initial electrical resistivity $(\sim 1250 \mu \Omega \cdot \mathrm{cm})$. The same dependence of the resistivity was shown for liquid state of the carbon at the highest input energy level (up to $110 \mathrm{MJ} / \mathrm{kg}$ ); the resistivity diminishing after the melting region and then rising (figure 4 ).

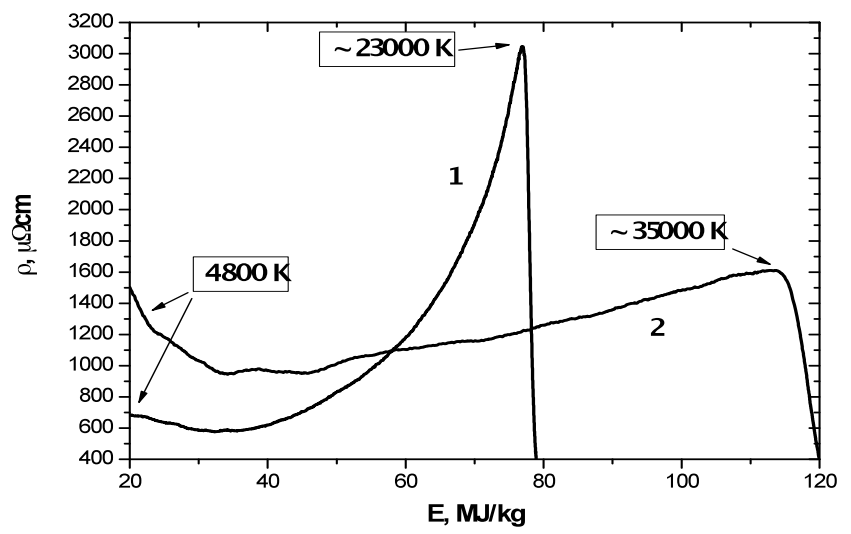

Fig.4. The comparison of resistivity under fast heating for two different specimens of graphite: anisotropic (curve $1, \mathrm{~V} / \mathrm{V}_{0}=$ 1.25; density $1.76 \mathrm{~g} / \mathrm{cm}^{3}$ ), and isotropic (curve $2, \mathrm{~V} / \mathrm{V}_{0}=1.45$; density $1.38 \mathrm{~g} / \mathrm{cm}^{3}$ ). Finish of melting is shown by the arrows $(4800 \mathrm{~K})$. There is a start of destruction for the sapphire tubes at the maximum of both curves.

The density for curve 1 is higher $\left(1.76 \mathrm{~g} / \mathrm{cm}^{3}\right)$ than for curve $2\left(1.38 \mathrm{~g} / \mathrm{cm}^{3}\right)$, and that is why the pulse pressure for curve 1 is higher and the destruction of the tube begins earlier.

The temperature $\mathrm{T}$ was roughly estimated through the $\mathrm{C}_{\mathrm{V}}=3 \mathrm{~J} / \mathrm{g} \cdot \mathrm{K}$ value (heat capacity under constant volume) that was measured earlier [7] just after melting at high pressure (near $50 \mathrm{kbar}$ ). An estimation of the high temperature (from the relationship $\Delta \mathrm{E}=\mathrm{C}_{\mathrm{V}} \times \Delta \mathrm{T}$ ), beginning at the melting temperature, gives at the maximum input energy $(75 \mathrm{MJ} / \mathrm{kg})$, a temperature $\mathrm{T}$ 
$23000 \mathrm{~K}$. We see that liquid carbon shows metal and non metal properties in the wide range of input energy and pressure.

\section{Data on the liquid metals properties}

As it appeared [8] liquid tungsten has the same effect as we have seen for liquid carbon. One can see in the figure 5 the results of fast heating tungsten wires in capillary tubes of different inner volume $\mathrm{V}$. $\left(\mathrm{V}_{0}-\right.$ the initial tungsten volume).

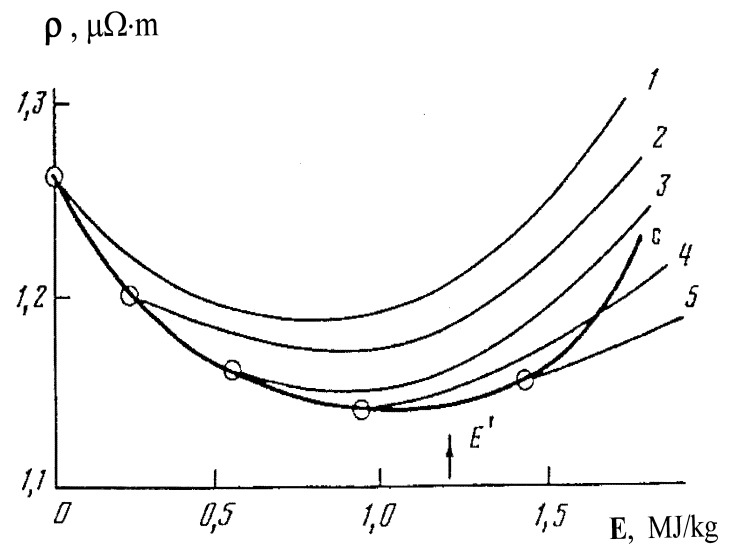

Fig. 5. Resistivity $\rho$ of liquid tungsten wires heated in capillary insulating tubes. $1-\mathrm{V} / \mathrm{Vo}=1.07 ; 2-1.13 ; 3-1.20 ; 4-$ $1.31 ; 5-1.54 . \mathrm{C}=$ free expansion (in the water). $\mathrm{E}=0$ (finish of melting). $\mathrm{d} \rho / \mathrm{dE}>0$ before $\mathrm{E}^{\prime}=1.20 \mathrm{MJ} / \mathrm{kg}$

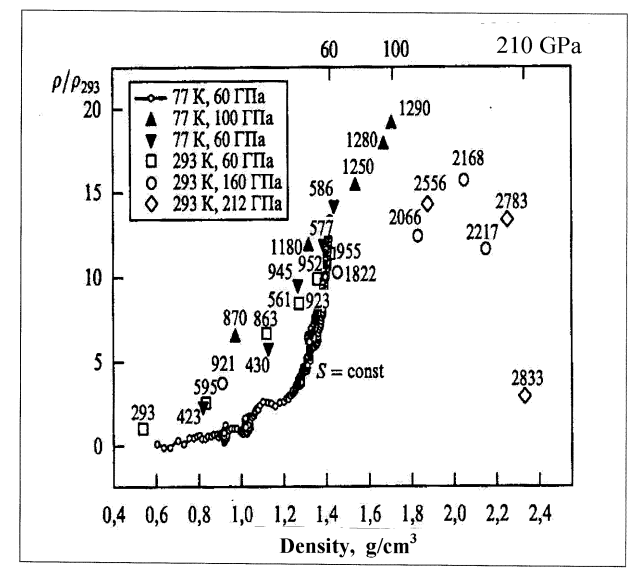

Fig. 6. Resistivity for Lithium at high pressures.

Liquid tungsten has the same effect: the more density is the more value of resistivity has the liquid phase of higher density.

Lithium has the same peculiarities as one can see in figure 6 [9]. Figures near the points show temperature (in $\mathrm{K}$ ).

For the comparison the data for liquid Aluminum are shown in figure 7 . This metal has the only metal-nonmetal transition near the referred densities at $\mathrm{V} / \mathrm{V}_{0} \sim 3$ 4. At higher $\mathrm{V} / \mathrm{V}_{0}$ one can see non metal behavior of the resistivity (it diminishes with rising of the temperature) [10].

The next progress in that theme with measuring pulse pressure on the shift of ruby line in the spectrum (up to $100 \mathrm{kbar}$ ) was published in [11].

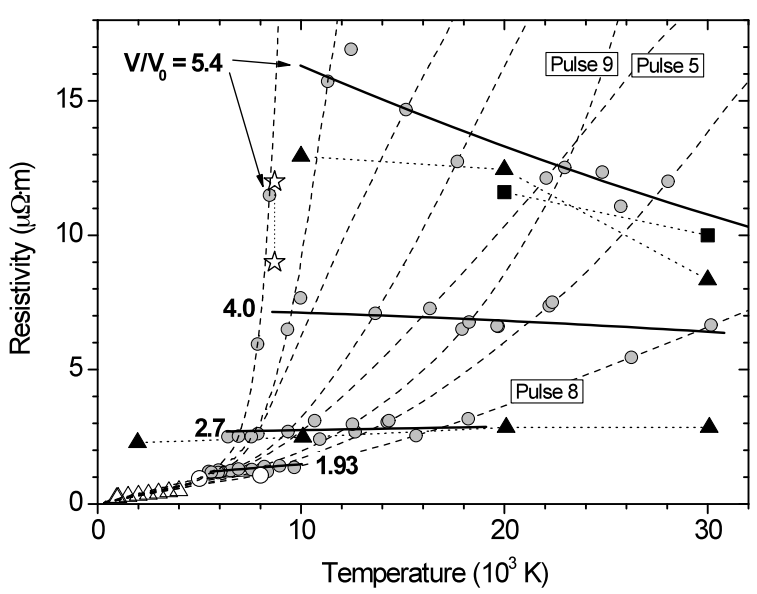

Fig. 7. Resistivity of liquid $\mathrm{Al}$ at the isochors (the transition from metal properties to plasma-like properties).

\section{Conclusion}

Liquid carbon (volume) density at the melting line under low pressures is rather small $\left.\sim 1.0-1.2 \mathrm{~g} / \mathrm{cm}^{3}\right)$. It is much higher $\left(1.8 \mathrm{~g} / \mathrm{cm}^{3}\right)$ at higher pressures $(\sim 54$ kbar).

The main achievement of our experiments at a high input energy $(40-110 \mathrm{~kJ} / \mathrm{g}$ ) is the dependence of the specific resistivity on the density: the higher the density, the higher the resistivity of the liquid carbon.

In experiments far above melting point during the isochoric process of heating (up to $\mathrm{E}=110 \mathrm{~kJ} / \mathrm{g}, \mathrm{T} \approx 35$, $000 \mathrm{~K}$ ), the derivative $\mathrm{d} \rho / \mathrm{dE}$ varies from negative to positive value in a wide range of high energy input $(\mathrm{E}=$ $30-50 \mathrm{~kJ} / \mathrm{g}$ ) for different densities.

It should be mentioned that the transition to metal-like properties at the maximum input energy (for example $\mathrm{E}$ $\sim 75 \mathrm{~kJ} / \mathrm{g}$, fig.3) leads to higher values of resistivity $\rho$ $(3000 \mu \cdot \Omega \mathrm{cm})$, which are higher than those for liquid semi-metal carbon near melting $(\sim 700-800 \mu \Omega \cdot \mathrm{cm}$, but for lower pressures and at lower temperatures).

Evidently, the increase of the resistivity under a high pressure (or/and for a higher density) is a common behavior for metals (Li,W), semi-metals, and semi conductors (carbon) in liquid state.

\section{Acknowledgments}

This work was supported by a scientific grant of Presidium of Russian Academy of Sciences (P-12) and by the Russian Fund on Basic Research, grant № 10-0800114a.

\section{References}

1. M.J.Kuchner and S.Seager, Astrophysical Journal Letters, 0504214, 2, May (2005)

2. Nikku Madhusudhan, Joseph Harrington, Kevin B. Stevenson, et al., Nature, 09602, December (2010)

3. A.I. Savvatimskiy AI. Carbon, 43(6): 1115-1142 (2005)

4. A.I. Savvatimskiy AI. J. Phys.: Condens. Matter, 20: 114112 (6 pp) (2008) 
5. M. Togaya Published in: VV. Brazhkin et al. (eds.), New Kinds of Phase Transitions: Transformations in Disordered Substances, 255, Kluver Academic Publishers (2002) High Press, 9. p. 331(1977)

7. V.N. Korobenko, A.I. Savvatimskiy, and R.Cheret, Int. J. Thermophys., 20(4) (1999)

8. V.V. Ivanov, S.V.Lebedev, A.I.Savvatimskiy Teplofizika Vysokikh Temperatur, 20, \#6, (1982, in Russian)

9. Maksimov E.G., M.V.Magnitzkaya, and V.E.Fortov, Physics Uspekhi, 175(8) (2005)

10. V. N. Korobenko, A. D. Rakhel, A. I. Savvatimskiy, and V. E. Fortov, Physical Review B, 71, 014208 (2005)

11. V.N. Korobenko, A.D. Rakhel, Physical Review B, 75, 064208 (2007) 